\title{
COMMISSION 36: THEORY OF STELLAR ATMOSPHERES
} (THÉORIE DES ATMOSPHĖRES STELLAIRES)

\author{
PRESIDENT: Dainis Dravins \\ VICE-PRESIDENT: Monique Spite \\ ORGANIZING COMMITTEE: Tom Ayres, Beatriz Barbuy, Lawrence \\ Cram, Dan Kiselman, John Landstreet, Roberto Pallavicini, Hideyuki \\ Saio, Christopher Sneden, Kazimierz Stepień, Klaus Werner
}

\section{The past triennium}

During 2000-2003, the Commission 36 Organizing Committee (OC) did evaluate a fairly large number of proposals for IAU meetings, recommending several among those, and discussing with different groups in the process of proposing conferences. It was particularly satisfying that a very broad and qualified program of stellar physics could be offered at the 2003 Sydney General Assembly.

The Report by Commission 36, published in the Reports on Astronomy vol. XXVA, was written in a somewhat different format from previous triennia. The choice between a more traditional and extended format, and a more compact one, was made following a discussion within the OC. The conclusion was that, since the breadth of the field now makes it infeasible to highlight more than a few small samples of it, this report would be shortened as compared to that of earlier triennia. It briefly describes areas and issues of current research, and also provides web links for obtaining further information. The latter were included only after some hesitation: on one hand, the widespread use of the world-wide-web in most parts of the astronomical world has made it a primary source for seeking introductions to the field but, on the other hand, web addresses have a tendency to be only short-lived, limiting the longer-term value of their publication.

\section{Membership and elections}

The total number of members amounts to about 325 . Some IAU members joined during the past triennium, and among the new IAU members elected at the Sydney GA, 15 had chosen this Commission as their primary one.

A certain effort was made in the election of new Commission officials. In order to enhance the participation of members in Commission matters, an invitation to propose names for new members of the future Organizing Committee was sent to all Commission members for whom e-mail addresses could be found. The OC then performed the final election among those names having received the larger number of nominations, but then taking into account also geographical and thematic coverage. A working rule was applied, such that any member can be reelected only once (for a second triennium), except if elected to President or Vice-President, but that the past President would be expected to serve for another triennium.

The following new officials were elected for 2003-2006: Monique Spite (Paris, France) - President; John Landstreet (London, Ontario, Canada) - Vice-President. 
Previous members remaining on the Organizing Committee are: Tom Ayres (Boulder, USA), Dainis Dravins (past President; Lund, Sweden), Dan Kiselman (Stockholm, Sweden), Christopher Sneden (Austin, USA), and Klaus Werner (Tübingen, Germany). New members joining the OC are: Martin Asplund (Canberra, Australia), Suchitra Balachandran (College Park, USA), Peter Hauschildt (Hamburg, Germany), K. N. Nagendra (Bangalore, India), and Gražina Tautvaišienè (Vilnius, Lithuania).

This election procedure took place before the new IAU rules for Commissions had been adopted: for forthcoming elections, the procedures may have to be modified, especially if the size of the OC is to be significantly reduced.

\title{
3. Business meeting in Sydney
}

The Business meeting of Commission 36 was held on July 21, attended by some 20 members, including the outgoing and incoming Presidents, and several members of the Organizing Committee. The topics for this meeting, in particular the discussion on topics for possible future conferences, had been announced also in the The Magellanic Times, the General Assembly's daily newspaper.

The issues presented included a review of the work made within Commission 36 , and the election of its new Organizing Committee. The possibility of establishing specific working groups was noted, but no immediate needs were identified. Also, some information was exchanged relevant for the training of young researchers, and about the availability of some databases of atmospheric models.

\subsection{Future scientific meetings during 2005-2007}

It was noted that, to a large extent, the actions by the OC's of various Commissions were mainly in responding to proposals for future meetings, rather than being "pro-active", and taking their own initiatives in trying to identify topics for promising future symposia or colloquia. To this end, an informal discussion was held, considering various possible topics that might perhaps become suitable for future Symposia, Colloquia, or Joint Discussions, perhaps during the General Assembly in Prague 2006. Topics discussed included, i.a., "The fine structure across stellar surfaces", "Quantum-optical effects in astrophysical radiation", "Atmospheres of non-spherical stars", "Physics of Population III stars", and others.

\subsection{Conclusion}

At the end, the outgoing President thanked the outgoing $\mathrm{OC}$ and the participating Commission 36 members for their activities, and welcomed Monique Spite as the new President for the next triennium.

\author{
Dainis Dravins \\ President of the Commission
}

